\title{
Acúmulo de macronutrientes pela cebola 'Optima' estabelecida por se- meadura direta
}

\author{
Diego R de Q Pôrto; Arthur Bernardes Cecílio Filho; André May; José Carlos Barbosa \\ UNESP-FCAV-Dep ${ }^{\text {to. }}$ Produção Vegetal, Via de acesso Prof. Paulo Donato Castellane, s/nº, 14884-900 Jaboticabal-SP; E-mail: \\ rutra@fcav.unesp.br
}

\section{RESUMO}

O objetivo do presente trabalho foi quantificar o acúmulo de macronutrientes pela cebola 'Optima', em cultura estabelecida por semeadura direta. O experimento foi conduzido na Fazenda Rio Doce, entre os municípios de Itobi e São José do Rio Pardo, SP. As amostragens de plantas foram realizadas aos 30, 50, 70, 90, 110, 130 e 150 dias após a semeadura (DAS), para determinação da massa seca e do acúmulo dos nutrientes (N, P, K, Ca, Mg e S). O acúmulo máximo estimado de massa seca da parte aérea e do bulbo foi de 5,70 g planta ${ }^{-1}\left(2.394,0 \mathrm{~kg} \mathrm{ha}^{-1}\right)$ e 13,17 g planta $^{-1}\left(5.531,4 \mathrm{~kg} \mathrm{ha}^{-1}\right)$, respectivamente, aos 150 DAS. A parte aérea e o bulbo contribuíram com aproximadamente $30 \%$ e $70 \%$, respectivamente, na massa seca da planta inteira ao final do ciclo. Os nutrientes $\mathrm{N}, \mathrm{P}, \mathrm{K}$ e S, acumularam-se preferencialmente no bulbo, enquanto $\mathrm{Ca}$ e $\mathrm{Mg}$ na parte aérea. A ordem decrescente de acúmulo dos nutrientes verificada para a cebola 'Optima' foi: $\mathrm{K}>\mathrm{N}>\mathrm{Ca}>\mathrm{S}>\mathrm{Mg}>\mathrm{P}$. Para uma população de 420.000 plantas ha $^{-1}$ e uma produtividade de $72 \mathrm{t} \mathrm{ha}^{-1}$, considerando-se os valores observados, verificou-se que o híbrido de cebola 'Optima' exportou pelo bulbo 35,0; 5,3; 68,9; 25,8; 5,6 e 21,9 $\mathrm{kg} \mathrm{ha}^{-1}$, respectivamente, de N, P, K, Ca, Mg e S.

Palavras-chave: Allium cepa L., crescimento, nutrição de plantas.

\begin{abstract}
Macronutrients accumulation by onion 'Optima' established by direct sowing

The objective of this research was to quantify under field conditions, the accumulation of macronutrients by onion 'Optima', in cultures established by direct sowing. The experiment was carried out at Rio Doce farm between the municipal districts of Itobi and São José do Rio Pardo, São Paulo State, Brazil. Samples were taken at the 30,50,70, 90,110, 130 and 150 days after sowing (DAS), for dry mass determination and accumulation of $\mathrm{N}, \mathrm{P}, \mathrm{K}, \mathrm{Ca}, \mathrm{Mg}$ and $\mathrm{S}$. The maximum estimated accumulation of shoot and bulb were of $5.70 \mathrm{~g}$ plant $^{-1}\left(2.394 .0 \mathrm{~kg} \mathrm{ha}^{-1}\right)$ and $13.17 \mathrm{~g} \mathrm{plant}^{-1}\left(5.531 .4 \mathrm{~kg} \mathrm{ha}^{-1}\right)$, respectively, at $150 \mathrm{DAS}$. At the end of the cycle, the average contribution of shoot and bulb were about $30 \%$ and $70 \%$, respectively. The nutrients $\mathrm{N}, \mathrm{P}, \mathrm{K}$ and $\mathrm{S}$, were accumulated preferably in the bulb; while $\mathrm{Ca}$ and $\mathrm{Mg}$, in the aerial part. The nutrients in decreasing order of accumulation verified for the onion 'Optima' were: $\mathrm{K}>\mathrm{N}>$ $\mathrm{Ca}>\mathrm{S}>\mathrm{Mg}>\mathrm{P}$. For a population of 420.000 plants $\mathrm{ha}^{-1}$ and a productivity of $72 \mathrm{tha}^{-1}$, and considering the observed values, it was verified that the onion 'Optima' hybrid exported by bulb 35.0; 5.3; 68.9 ; 25.8; 5.6 e $21.9 \mathrm{~kg} \mathrm{ha}^{-1}$, respectively, of $\mathrm{N}, \mathrm{P}, \mathrm{K}, \mathrm{Ca}, \mathrm{Mg}$ and $\mathrm{S}$.
\end{abstract}

Keywords: Allium cepa L., growth, plant nutrition.

(Recebido para publicação em 15 de fevereiro de 2006; aceito em 12 de dezembro de 2006)

$\mathrm{N}^{0}$ Brasil, a cebola é considerada a terceira hortaliça mais importante em termos de valor econômico, atrás apenas da batata e do tomate (Boeing, 2002).

Em seu cultivo têm havido modificações no modo de produção, objetivando tanto o aumento de produtividade e/ou de qualidade do bulbo, quanto a minimização dos custos, com influência direta sobre a rentabilidade da cultura e a viabilidade econômica da atividade. Entre os vários fatores que influenciam os três pontos citados, a implantação da cultura por semeadura direta tem recebido maior atenção dos produtores, sobretudo pelo avanço percebido na área de mecanização, e na redução de mão-de-obra e operações demandadas para a formação e o transplantio, de mudas de cebola. Paralelamente, surge a necessidade de conhecer o cresci- mento da cultura nesta condição de cultivo, de modo a otimizar os benefícios que as práticas culturais poderão proporcionar.

O conhecimento dos padrões de acúmulo de matéria seca de uma cultura possibilita melhor entendimento dos fatores relacionados com a nutrição mineral e conseqüentemente com a adubação, visto que, a absorção de nutrientes é influenciada pela taxa de crescimento da planta (Glass, 1989; Marschner, 1995).

A determinação da quantidade de nutrientes acumulados nas plantas, principalmente na parte colhida, é importante para se avaliar a remoção dos nutrientes da área de cultivo e tornou-se um dos componentes necessários para as recomendações econômicas de adubação. Em geral, a absorção de nutrientes é diferenciada ao longo do ciclo, inten- sificando-se no florescimento, na formação e no crescimento dos frutos ou do órgão de reserva que será colhido. Por isso, além da quantidade absorvida de nutrientes, deve ser considerada também, a sua concentração nos diferentes estádios de desenvolvimento (Haag et al., 1981; Vitti et al., 1994; Malavolta et al., 1997).

A exigência nutricional pode variar entre cultivares e a extração de nutrientes e sua relação com crescimento podem ser diferentes em razão da classe de solo, do sistema de cultivo, e ainda, variar segundo a produtividade e o ciclo da cultura (Vidigal et al., 2003).

Segundo Pereira \& Fontes (2005), a quantidade de nutrientes absorvida por uma cultura é função da concentração do nutriente na matéria seca e da produção de massa seca de cada órgão da planta por unidade de área. Com base na quan- 
tidade de nutriente extraída pela cultura e a eficiência de recuperação de cada nutriente aplicado serão determinadas as doses dos fertilizantes. Para a maioria das espécies olerícolas, o N e o K são os nutrientes mais extraídos e perdidos por lixiviação, sendo necessário, muitas vezes, a adição de quantidade elevada dos mesmos como fertilizantes.

Haag et al. (1970), estudando o crescimento e o acúmulo de nutrientes da cultivar de cebola 'Baia Periforme Precoce de Piracicaba' em casa de vegetação, num ciclo de cultivo superior a 190 dias, observaram que o acúmulo de nutrientes acompanhou o acúmulo de matéria seca. A cebola tem crescimento lento até próximo à metade do ciclo (Haag et al., 1970; Wiedenfeld, 1994) e, a partir daí, tem-se o início da bulbificação (Gamiely et al., 1991), quando se inicia a translocação de fotoassimilados e outros compostos para o bulbo, havendo rápido acúmulo de matéria seca no bulbo (Brewster, 1994).

Vidigal et al. (2002), avaliando o crescimento e a marcha de acúmulo de nutrientes da cultivar 'Alfa Tropical', num ciclo de cultivo de 130 dias, observaram que a cebola cultivada no verão cresceu lentamente até próximo à metade do ciclo e que, após esse período, o crescimento foi intensificado. A ordem de extração dos macronutrientes pela cebola foi: $\mathrm{K}>\mathrm{N}>\mathrm{Ca}>\mathrm{S}>\mathrm{P}>\mathrm{Mg}$, na parte aérea e $\mathrm{K}>\mathrm{N}>\mathrm{Ca}>\mathrm{P}>\mathrm{S}>\mathrm{Mg}$, no bulbo. Goto (1983), estudando o efeito da adubação orgânica combinada com adubação mineral em cebola, verificou a seguinte ordem de acúmulo de nutrientes: $\mathrm{K}>\mathrm{N}>\mathrm{P}>\mathrm{Ca}>\mathrm{Mg}>\mathrm{S}$, na parte aérea e $\mathrm{N}>\mathrm{Ca}>\mathrm{K}>\mathrm{Mg}>\mathrm{P}>\mathrm{S}$, no bulbo.

Diante do exposto, o presente trabalho objetivou quantificar o acúmulo de macronutrientes pela cebola 'Optima' estabelecida por semeadura direta.

\section{MATERIAL E MÉTODOS}

O experimento foi conduzido na Fazenda Rio Doce entre os municípios de Itobi e São José do Rio Pardo, SP, com latitude Sul 21³7'16", longitude Oeste 46 $6^{\circ}$ ' $15^{\prime \prime}$ e altitude de aproximadamente $900 \mathrm{~m}$, no período de março a agosto de 2004. O clima da região é do tipo tropical com inverno seco, classificado como Aw segundo Köppen, descrito por Vianello \& Alves (1991). A precipitação média anual situa-se em torno de $1.400 \mathrm{~mm}$, e as temperaturas médias anuais máxima e mínima são de $31,6^{\circ} \mathrm{C}$ e $17,9^{\circ} \mathrm{C}$, respectivamente.

O solo da área experimental é classificado como LATOSSOLO VERMELHO-AMARELO Eutrófico (EMBRAPA, 1999). Foram retiradas amostras compostas de solo, do local do experimento antes da implantação da cultura na camada de 0 a $0,2 \mathrm{~m}$. A análise química do solo coletado foi feita pelo Departamento de Solos e Adubos, UNESP, Campus de Jaboticabal, e revelou os seguintes resultados: $\mathrm{pH}$ $\left(\mathrm{CaCl}_{2}\right)=5,2 ;$ M.O. $=25 \mathrm{~g} \mathrm{dm}^{-3} ; \mathrm{P}$ (resina) $=24 \mathrm{mg} \mathrm{dm}^{-3} ; \mathrm{K}=1,4 \mathrm{mmol}_{\mathrm{c}} \mathrm{dm}^{-3}$; $\mathrm{Ca}=31 \mathrm{mmol}_{\mathrm{c}} \mathrm{dm}^{-3} ; \mathrm{Mg}=10 \mathrm{mmol}_{\mathrm{c}} \mathrm{dm}^{-3}$; $\mathrm{H}+\mathrm{Al}=28 \mathrm{mmol}_{\mathrm{c}} \mathrm{dm}^{-3} ; \mathrm{SB}=42,4 \mathrm{mmol}_{\mathrm{c}}$ $\mathrm{dm}^{-3} ; \mathrm{T}=70,4 \mathrm{mmol} \mathrm{dm}^{-3}$ e $\mathrm{V}=60 \%$.

$\mathrm{O}$ experimento foi instalado sob delineamento de blocos casualizados, avaliando-se a cultura em sete épocas (30, 50, 70, 90, 110, 130 e 150 dias após a semeadura), com três repetições. A unidade experimental teve área de 2,6 m², correspondendo a 2,16 m de comprimento por 1,2 $\mathrm{m}$ de largura.

O preparo do solo constou de uma aração e duas gradagens, sendo a primeira operação realizada para a incorporação do calcário, cuja dose foi calculada visando elevar a $80 \%$ a saturação de bases do solo (Trani \& Raij, 1997).

No plantio foram aplicados $30 \mathrm{~kg} \mathrm{ha}^{-1}$ de N, $300 \mathrm{~kg} \mathrm{ha}^{-1}$ de $\mathrm{P}_{2} \mathrm{O}_{5}$ conforme Trani \& Raij (1997). Ainda no plantio, foram aplicados $40 \mathrm{~kg} \mathrm{ha}^{-1}$ de $\mathrm{K}_{2} \mathrm{O}$ e $1,0 \mathrm{~kg} \mathrm{ha}^{-1}$ de B. Em cobertura foram aplicados 70 $\mathrm{kg} \mathrm{ha}^{-1}$ de $\mathrm{N}$ e $110 \mathrm{~kg} \mathrm{ha}^{-1}$ de $\mathrm{K}_{2} \mathrm{O}$, parcelada em quantidades iguais, aos 30 , 45 e 60 dias após a semeadura (DAS). Foram utilizados os fertilizantes nitrato de amônio, superfosfato simples, cloreto de potássio e bórax, para o fornecimento de $\mathrm{N}, \mathrm{P}, \mathrm{K}$ e $\mathrm{B}$, respectivamente. Os adubos foram aplicados dois dias antes da semeadura e posteriormente incorporados com auxílio de encanteiradora tratorizada. O bórax, foi aplicado com o auxílio de um pulverizador costal com distribuição em área total, anteriormente ao encanteiramento do local.
A semeadura foi realizada em 08-032004, diretamente em canteiro com cinco linhas de plantio. Adotou-se o espaçamento de 0,275 x 0,06 m resultando em 60 plantas $\mathrm{m}^{-2}$. Em pequenas covas de $1 \mathrm{~cm}$ de diâmetro e $1 \mathrm{~cm}$ de profundidade, abertas com auxílio de um coveador de estrutura em ferro, gabaritado para as dimensões e espaçamentos desejados, fez-se o semeio de 5 a 7 sementes, cobrindo-as com terra do próprio canteiro. Aos 21 dias após a semeadura, e 11 dias da emergência das plântulas, foi realizado o desbaste, deixando-se uma planta a cada 0,06 m. Foi utilizado o híbrido 'Optima', sendo um dos dois materiais mais cultivados no município. As irrigações foram diárias durante as primeiras semanas após o semeio e a cada quatro dias em complementação às precipitações, sendo o sistema utilizado o de aspersão convencional.

As plantas foram avaliadas no período de 30 a 150 DAS (05-08-2004), época em que se realizou a última coleta determinada pelo tombamento da parte aérea ("estalo" do pseudocaule). Nas coletas, com intervalos de 20 dias, foram amostradas cinco plantas competitivas por unidade experimental. Após cada coleta, as plantas foram lavadas em água corrente; água desionizada $+1 \mathrm{ml}$ $\mathrm{L}^{-1}$ de detergente neutro; água desionizada $+0,01 \mathrm{~mol} \mathrm{~L}^{-1} \mathrm{de} \mathrm{HCl}$; água desionizada e água desionizada novamente, em seguida, bulbo e parte aérea foram separados e secos em estufa com circulação forçada de ar à temperatura de $65^{\circ} \mathrm{C} \pm 1^{\circ} \mathrm{C}$, por cinco dias. Após a secagem, procedeu-se a moagem do material em moinho de aço inoxidável tipo Wiley, com peneira de malha $1 \mathrm{~mm}$. O material moído foi digerido conforme metodologia descrita por Bataglia et al. (1983) para a determinação dos teores de macronutrientes na parte aérea e no bulbo. Calculou-se a quantidade dos macronutrientes mediante o produto entre o teor e a massa seca correspondente a cada parte da planta e época avaliada. Os valores das quantidades de nutrientes foram expressos em mg plan$\mathrm{ta}^{-1}$ e $\mathrm{kg} \mathrm{ha}^{-1}$. Para cálculo da quantidade de nutrientes por área, considerou-se $7.000 \mathrm{~m}^{2}$ efetivamente cultivados em 1 hectare (420.000 plantas), cuja perda de 


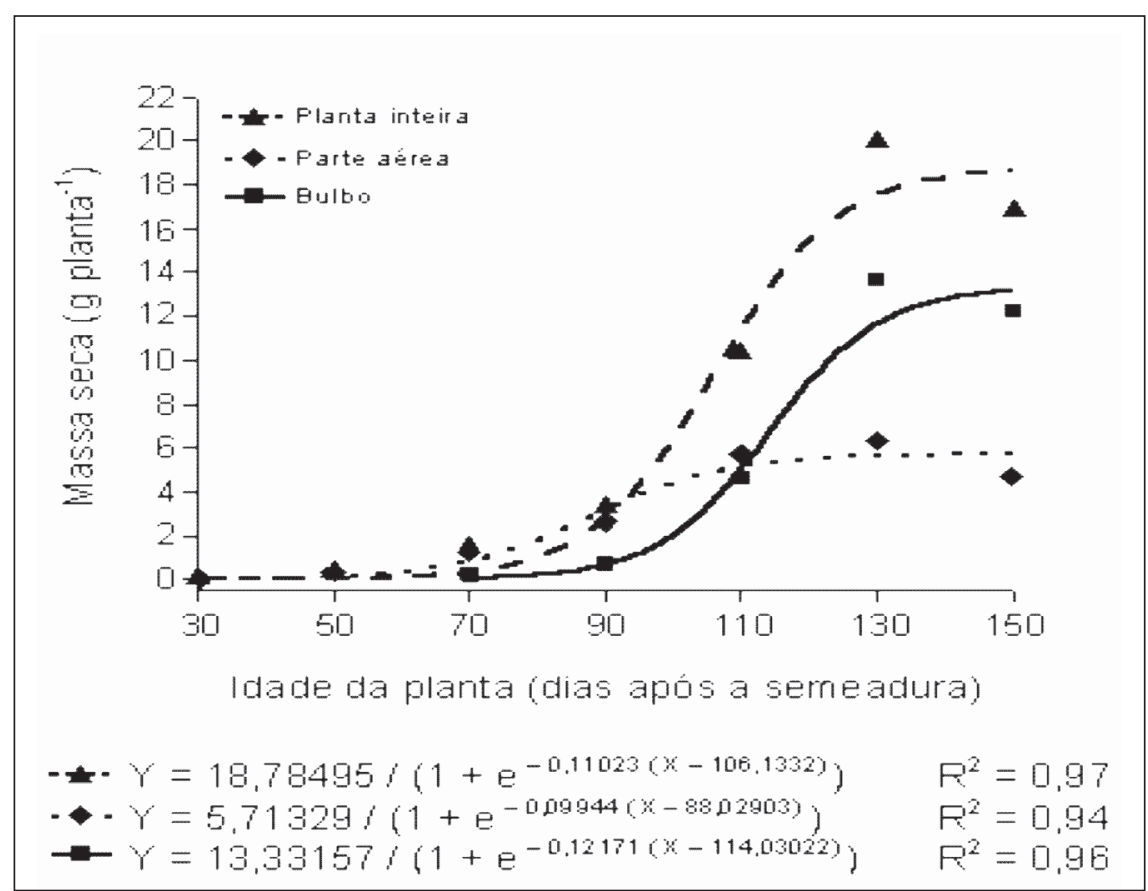

Figura 1. Acúmulo de massa seca em planta de cebola 'Optima' ao longo do ciclo, em cultura estabelecida por semeadura direta. São José do Rio Pardo-SP, UNESP, 2004.

área $\left(3.000 \mathrm{~m}^{2}\right)$ correspondeu aos espaços entre canteiros.

As marchas de acúmulo de massa seca e dos macronutrientes ao longo do ciclo foram obtidas ajustando-se os acúmulos do nutriente de cada época de avaliação, utilizando-se o programa gráfico ‘Origin 6.0' pelo modelo logístico, não linear, que obedece a seguinte equação: $\mathrm{Y}=\mathrm{a} /\left(1+e^{-\mathrm{K}(\mathrm{X}-\mathrm{XC})}\right)$, onde: $\mathrm{a}=$ máximo assintótico (acúmulo ou crescimento máximo), $e=$ base do logaritmo neperiano, $\mathrm{k}=$ taxa média de crescimento; $\mathrm{x}=$ tempo (dias); $\mathrm{xc}=$ tempo necessário para atingir metade do crescimento máximo. Os critérios utilizados para ajuste das equações foram o maior coeficiente de determinação $\left(\mathrm{R}^{2}\right)$ e a menor soma de quadrados dos desvios dos valores observados em relação aos valores estimados pela curva.

\section{RESULTADOS E DISCUSSÃO}

O acúmulo de massa seca da parte aérea (MSPA) apresentou, assim como a massa seca de bulbo (MSB), três fases distintas; mas com diferenças quanto ao número de dias de cada fase, bem como quanto a magnitude do acúmulo de massa, sobretudo na segunda fase (Figura 1).
$\mathrm{Na}$ primeira fase da marcha de acúmulo de massa seca da parte aérea e do bulbo, ambos acumularam quantidades muito pequenas em relação aos máximos acumulados pelos respectivos segmentos do vegetal. O número de dias desse período para MSPA foi de 40 dias (30 a 70 DAS); enquanto para MSB, de apenas 20 dias (70 a 90 DAS).

A segunda fase foi marcada pelo maior acúmulo de massa seca. Na parte aérea, que ocorreu de 70 a 110 DAS, foram acumuladas 4,32 $\mathrm{g} \mathrm{planta}^{-1} \mathrm{de}$ massa seca, o que correspondeu a 75,8\% do total acumulado na parte aérea da cebola. No bulbo, o período foi dos 90 aos 130 DAS e houve acúmulo de $11,0 \mathrm{~g}$ planta $^{-1}$, equivalente a $83,4 \%$ do total de MSB ao final do ciclo. Nesse período, o incremento médio diário de massa seca no bulbo foi de 274,57 mg planta ${ }^{-1}$, o que corresponde a 131,2 kg de massa seca de bulbo por dia, em 1 hectare com 420.000 plantas (60 plantas $\mathrm{m}^{-2}$ ).

A terceira fase de acúmulo de massa seca pela cebola foi caracterizada por pequeno acúmulo de massa e durou 40 dias para a parte aérea (110 a 150 DAS) e 20 dias para bulbo (130 a 150 DAS). Nessa fase há praticamente supressão do crescimento da parte aérea e forte desaceleração no incremento de MSB, justificado no primeiro caso pela perda da posição de dreno principal para o bulbo e, no segundo caso, pela aproximação da colheita, com alterações no bulbo principalmente de ordem qualitativa (maturação) em sobreposição à quantitativa.

O acúmulo máximo estimado de massa seca da planta inteira foi de 18,64 g planta $^{-1}\left(7.829 \mathrm{~kg} \mathrm{ha}^{-1}\right)$, obtido aos 150 DAS. As contribuições da parte aérea e do bulbo para a massa seca de planta inteira ao final do ciclo foram de, respectivamente, $30 \%$ e $70 \%$. Os valores de acúmulo máximo estimado de massa seca da parte aérea e do bulbo foram de 5,70 g planta $^{-1}\left(2.394 \mathrm{~kg} \mathrm{ha}^{-1}\right)$ e 13,17 g planta $^{-1}\left(5.531 \mathrm{~kg} \mathrm{ha}^{-1}\right)$, respectivamente, aos 150 DAS (Figura 1). Esses resultados se assemelham aos obtidos por Vidigal et al. (2002), em que as contribuições da massa seca da parte aérea e do bulbo foram de aproximadamente $36 \%$ e $64 \%$, respectivamente, para massa seca total. $\mathrm{O}$ acúmulo de massa seca da planta inteira aos 30 DAS (fase inicial) foi de 4,3 mg. Este resultado corrobora com o obtido por Tei et al. (1996), que avaliaram o crescimento de cebola e verificaram um acúmulo médio de massa seca de três cultivos, sem limitações de água e de nutrientes, de 4,4 $\mathrm{mg}_{\text {planta }}{ }^{-1}$ na fase inicial dos ciclos, até próximo aos 40 dias após a emergência (DAE). Já no final do ciclo, 150 DAE, Tei et al. (1996) verificaram acúmulo médio de massa seca de $31,6 \mathrm{~g}$ planta $^{-1}$, valor bastante superior ao observado neste trabalho, 18,6 $\mathrm{g}_{\text {planta }}{ }^{-1}$ ao final do ciclo da cultura 150 DAS.

Entre as épocas de avaliações do crescimento da cebola, a maior taxa de acúmulo de massa seca da parte aérea ocorreu dos 70 aos 90 DAS e foi de $116,01 \mathrm{mg}$ planta $^{-1} \mathrm{dia}^{-1}\left(48,72 \mathrm{~kg} \mathrm{ha}^{-1}\right.$ $\left.\mathrm{dia}^{-1}\right)$. A maior taxa de acúmulo de massa seca do bulbo foi de $329,95 \mathrm{mg}$ planta $^{-1}$ dia $^{-1}\left(138,58 \mathrm{~kg} \mathrm{ha}^{-1} \mathrm{dia}^{-1}\right)$ no período de 110 a 130 DAS. Para a planta toda, a maior taxa de acúmulo de massa foi de 432,49 mg planta ${ }^{-1}$ dia $^{-1}(181,65 \mathrm{~kg}$ ha $^{-1}$ dia $^{-1}$ ), no período de 90 a 110 DAS. Da semeadura até 90 DAS, as taxas de acúmulo de massa seca da parte aérea foram maiores que as taxas observadas para a parte subterrânea e a partir dessa época, as taxas de acúmulo de massa 
seca no bulbo superaram as taxas de acúmulo na parte aérea.

A curva de acúmulo total (parte aérea e bulbo) de nutrientes pela planta de cebola assemelhou-se à curva de acúmulo de massa seca, descrevendo modelo de ajuste sigmoidal. Haag et al. (1970), estudando o crescimento e o acúmulo de nutrientes em cebola 'Baia Periforme Precoce de Piracicaba', também observaram o mesmo comportamento. Entretanto, embora similares quanto ao modelo de ajuste da curva, enquanto até 90 DAS houve acúmulo de aproximadamente $15 \%$ do total da massa seca acumulada na planta, para nutrientes os percentuais de acúmulo, na mesma época, variaram de 28 a 58\% do total acumulado pela planta. Mesmo assim, elevados percentuais do acúmulo total de nutrientes ocorreram nos últimos 60 dias do ciclo, sendo de 42, 64, 49, 67, 72 e $67 \%$ para N, P, K, Ca, Mg e $\mathrm{S}$, respectivamente.

$\mathrm{O}$ nitrogênio foi o segundo nutriente mais acumulado, $159,12 \mathrm{mg}$ planta $^{-1}$ (Figura 2A). De acordo com Filgueira (2003), o nitrogênio normalmente é o segundo macronutriente mais requerido pelas culturas olerícolas. Vidigal et al. (2002), trabalhando com cebola 'Alfa Tropical', também constataram que o nitrogênio foi o segundo macronutriente mais acumulado, com 218 mg planta $^{-1}$. De acordo com os valores observados ao final do ciclo, do total presente na planta, aproximadamente $43 \%$ e $57 \%$ encontravam-se, respectivamente, na parte aérea e no bulbo. Entretanto, os períodos de maior demanda diferiram nas duas partes da planta. Enquanto na parte aérea pode-se atribuir ao período de 50 a 90 DAS como o de maior requerimento de N; no bulbo, este período limitou-se a 20 dias (90 a 110 DAS). $\mathrm{O}$ fato de o bulbo ter apresentado uma quantidade de nitrogênio pouco maior que a parte aérea ao final do ciclo pode ser atribuído à redistribuição do $\mathrm{N}$ da parte aérea para o bulbo.

$\mathrm{O}$ fósforo foi o macronutriente acumulado em menor quantidade, $21,18 \mathrm{mg}$ planta $^{-1}$, aos 150 DAS. O período de maior acúmulo para esse nutriente foi de 70 a 130 DAS (Figura 2B). De acordo com os valores observados, a participação do bulbo no acúmulo total de $\mathrm{P}$

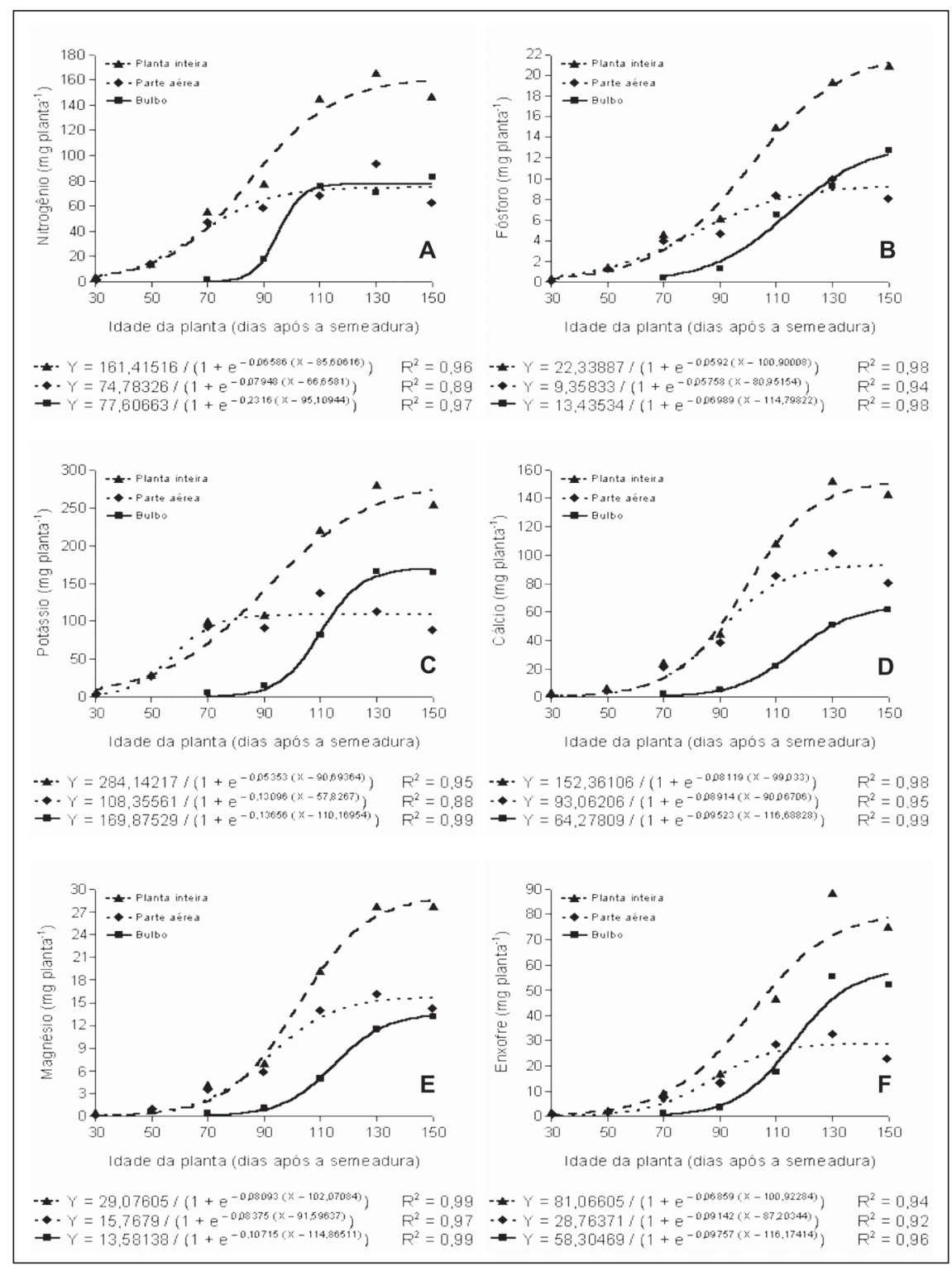

Figura 2. Acúmulo de nitrogênio (A), fósforo (B), potássio (C), cálcio (D), magnésio (E) e enxofre (F) em planta de cebola 'Optima' ao longo do ciclo, em cultura estabelecida por semeadura direta. São José do Rio Pardo-SP, UNESP, 2004.

foi de aproximadamente $61 \%$, enquanto a parte aérea contribuiu com cerca de $39 \%$ do P. O acúmulo de N na parte aérea tem seu incremento praticamente suprimido a partir de 90 DAS, no entanto, para P isto ocorreu 20 dias após, ou seja, 110 DAS. Observa-se que o P praticamente deixa de ser acumulado na parte aérea. Ao contrário, no bulbo, o acúmulo é contínuo até a colheita.

O potássio foi o nutriente acumulado em maior quantidade pela cebola, 272,74 mg planta ${ }^{-1}$ (Figura 2C). Vidigal et al. (2002) obtiveram resultado semelhante com a cultivar 'Alfa Tropical' onde o acúmulo máximo de potássio foi de 267 mg planta ${ }^{-1}$. Considerando os valores observados, do total de potássio acumulado ao final do ciclo da cultura, o bulbo contribuiu com aproximadamente $65 \%$ $\left(164,14 \mathrm{mg} \mathrm{planta}^{-1}\right)$. De acordo com Fontes (1998) e Filgueira (2003) o potássio é o macronutriente mais acumulado pela maioria das hortaliças. Aalta exigência em potássio por culturas que armazenam compostos orgânicos nos bulbos, como é o caso da cebola, pode também ser explicada pela sua importante função no transporte de fotoassimilados das folhas para os órgãos de reserva (Faquin, 1994).

A maior demanda de $\mathrm{K}$ pela planta situou-se no período de 70 a 110 DAS. 
Nesse período, a planta acumulou $139,03 \mathrm{mg}$, o equivalente a $51 \%$ do total acumulado pela planta. A taxa média de acúmulo de K entre 70 e 110 DAS foi de 3,47 mg planta dia-1 $\left(1,46 \mathrm{~kg} \mathrm{ha}^{-1}\right.$ dia $\left.^{-1}\right)$ muito superior à taxa de $1,49 \mathrm{mg}$ planta dia $^{-1}$ no período antecessor (30 a 70 DAS). Para as diferentes partes da planta, os períodos de maiores demandas de $\mathrm{K}$ pela parte aérea e bulbo foram, respectivamente, 50 a 70 DAS e 90 a 130 DAS.

$\mathrm{O}$ cálcio, terceiro nutriente mais absorvido pela planta, atingiu a quantidade de $149,97 \mathrm{mg}$ planta $^{-1}$ no fim do ciclo, com maiores incrementos entre os $70 \mathrm{e}$ 130 DAS (Figura 2D). Nesse período, o acúmulo de Ca correspondeu a $85 \%$ do total acumulado na planta inteira. $\mathrm{Na}$ parte aérea, o período de maior demanda ocorreu dos 70 aos 110 DAS enquanto no bulbo esse período foi de 90 a 130 DAS. Diferentemente do N, P e K, ao final do ciclo, a parte aérea acumulou maior quantidade de cálcio, sendo esta responsável por aproximadamente $57 \%$, enquanto o bulbo por cerca de $43 \%$ do total acumulado na planta inteira, considerando-se os valores observados ao fim do ciclo. Este padrão de distribuição do Ca é, portanto, resultado da redistribuição do nutriente ser praticamente nula (Marschner, 1995). Outro fator que pode acentuar essa diferença nas quantidades de Ca na parte aérea e bulbo é a competição entre K e Ca que se faz também dentro da planta (Malavolta et al., 1997). O maior fluxo de potássio para o bulbo concorre para diminuir a presença de cálcio neste órgão.

$\mathrm{O}$ acúmulo de $\mathrm{Mg}$ na planta foi de 28,49 $\mathrm{mg}$ planta $^{-1}$ no fim do ciclo, com maior demanda entre os 70 e 130 DAS (Figura 2E). À semelhança do Ca, a parte aérea acumulou relativamente maior quantidade de $\mathrm{Mg}$ que o bulbo. De acordo com os valores observados, a parte aérea acumulou aproximadamente 52\% do $\mathrm{Mg}$, enquanto o bulbo acumulou cerca de $48 \%$ do Mg total. A parte aérea apresentou maior demanda no período compreendido entre 70 e 110 DAS, com incrementos de 0,269 mg planta ${ }^{-1}$ dia $^{-1}$, já o bulbo apresentou maior demanda entre 90 e 130 DAS, com incrementos de 0,261 mg planta-1 dia $^{-1}$.

O enxofre acumulado pela planta atingiu a quantidade de 78,36 mg plan- $\mathrm{ta}^{-1}$ no fim do ciclo, com maior demanda entre os 70 e 130 DAS (Figura 2F). Houve maior demanda de $\mathrm{S}$ na parte aérea no período compreendido entre 70 e 110 DAS; já no bulbo esse período foi dos 90 aos 130 DAS, com incrementos de $0,516 \mathrm{mg}_{\text {planta }}{ }^{-1}$ dia $^{-1}$ e $1,052 \mathrm{mg}$ planta $^{-1} \mathrm{dia}^{-1}$, respectivamente, durante esse período. Assim como o N, P e K e diferente do observado para $\mathrm{Ca}$ e $\mathrm{Mg}$, o acúmulo de $\mathrm{S}$ foi maior no bulbo, cerca de $70 \%$. Na parte aérea, o acúmulo foi aproximadamente $30 \%$ do S total na colheita. Esse resultado está de acordo com os obtidos por Nasreen et al. (2003), os quais verificaram que o enxofre acumulou-se mais no bulbo, ao final do ciclo da cultura. Segundo os autores, do total de enxofre acumulado na planta inteira aos 90 DAT (145 DAS), $12 \%$ encontravam-se nas folhas e $82 \%$ no bulbo. Para estes mesmos autores, o aumento do acúmulo de enxofre no bulbo à medida que a planta atingiu a fase de maior desenvolvimento fotossintético foi por causa do crescimento foliar adequado o que permitiu uma ótima translocação e partição de fotossintatos das folhas para os bulbos que resultaram em maior tamanho de bulbo com uma maior matéria seca. A cebola é uma planta exigente em S, e geralmente esse nutriente é o terceiro ou quarto em ordem decrescente de acúmulo. Já em alface e berinjela, entre outras hortaliças, o enxofre é o macronutriente menos acumulado na planta (Malavolta, 1980). O enxofre afeta o sabor e o aroma de certas hortaliças condimentares, como cebola, cebolinha e alho. Isso ocorre porque o $\mathrm{S}$ é constituinte dos aminoácidos cistina, cisteína e metionina, precursores de compostos sulfurados voláteis responsáveis pelo aroma característico da cebola (Malavolta et al., 1997).

Os nutrientes N, P, K e S acumularam-se preferencialmente no bulbo, enquanto $\mathrm{Ca}$ e $\mathrm{Mg}$ na parte aérea. A ordem decrescente de acúmulo dos nutrientes verificada para a cebola 'Optima' foi: $\mathrm{K}>\mathrm{N}>\mathrm{Ca}>\mathrm{S}>\mathrm{Mg}>\mathrm{P}$. Este resultado foi semelhante aos obtidos por vários autores quando se trata da sequiência do acúmulo de $\mathrm{K}, \mathrm{N}$ e $\mathrm{Ca}$. Vidigal et al. (2002) constataram a seguinte ordem de acúmulo de nutrientes pela cebola 'Alfa Tropical': $\mathrm{K}>\mathrm{N}>\mathrm{Ca}$
> S > P > Mg. Já Zink (1962) constatou para cebola 'Southport White Globe': $\mathrm{K}>\mathrm{N}>\mathrm{Ca}>\mathrm{P}>\mathrm{Na}>\mathrm{Mg}$. Por outro lado, Haag et al. (1970) verificaram K $>\mathrm{N}>\mathrm{S}>\mathrm{P}>\mathrm{Mg}>\mathrm{Ca}$.

Para uma população de 420.000 plantas ha ${ }^{-1}$ e uma produtividade de $72 \mathrm{t}$ $\mathrm{ha}^{-1}$ considerando-se os valores observados, verificou-se que o híbrido de cebola 'Optima' extraiu, ao final do ciclo da cultura (150 DAS): 61,22; 8,74; 106,$18 ; 59,45 ; 11,56$ e $31,55 \mathrm{~kg} \mathrm{ha}^{-1}$, respectivamente, de $\mathrm{N}, \mathrm{P}, \mathrm{K}, \mathrm{Ca}, \mathrm{Mg}$ e S. O híbrido 'Optima' exportou pelo bulbo cerca de $57 \%$ do N, $61 \%$ do P, $65 \%$ do K, $43 \%$ do $\mathrm{Ca}, 48 \%$ do $\mathrm{Mg}$ e $70 \%$ do $\mathrm{S}$, o que correspondeu a 35,0 ; 5,$3 ; 68,9 ; 25,8 ; 5,6$ e $21,9 \mathrm{~kg} \mathrm{ha}^{-1}$, respectivamente. Portanto, constata-se que a ordem decrescente de macronutriente extraído pela cebola 'Optima' foi à mesma observada para a exportação.

Para uma população de 166.666 plantas ha' ${ }^{-1}$, Haag et al. (1970) verificaram as seguintes quantidades de nutrientes, em $\mathrm{kg} \mathrm{ha}^{-1}$, extraídas pela planta inteira: 132,8 de N; 21,9 de P; 177 de K; 15,9 de $\mathrm{Ca} ; 17,8$ de $\mathrm{Mg}$ e 33,8 de $\mathrm{S}$. Nesse caso, a ordem de extração foi: $K$ $>\mathrm{N}>\mathrm{S}>\mathrm{P}>\mathrm{Mg}>\mathrm{Ca}$. Vidigal et al. (2002), considerando uma população de 700.000 plantas ha $^{-1}$, citam as seguintes quantidades de nutrientes exportadas pelos bulbos: $69,66 \mathrm{~kg} \mathrm{ha}^{-1}$ de N; 14,50 $\mathrm{kg} \mathrm{ha}^{-1}$ de P; 57,09 $\mathrm{kg} \mathrm{ha}^{-1}$ de K; 24,67 $\mathrm{kg} \mathrm{ha}^{-1}$ de Ca; 4,47 $\mathrm{kg} \mathrm{ha}^{-1}$ de Mg e 12,07 $\mathrm{kg} \mathrm{ha}^{-1}$ de S. A ordem de exportação foi: $\mathrm{N}>\mathrm{K}>\mathrm{Ca}>\mathrm{P}>\mathrm{S}>\mathrm{Mg}$. Os bulbos participaram com cerca de $56 \%$ do N, $68 \%$ do P, $44 \%$ do K, $39 \%$ do Ca, $53 \%$ do $\mathrm{Mg}$ e $60 \%$ do S do total extraído pela planta inteira.

A quantidade de macronutrientes extraída pelos bulbos de cebola 'Optima' estabelecida por semeadura direta representa importante componente de retirada de nutrientes do solo, e sua avaliação deve ser utilizada para calibrar a quantidade de nutrientes à serem repostos, através de programas de adubação.

\section{AGRADECIMENTOS}

À Capes pela concessão de bolsa ao primeiro autor e à FAPESP pelo auxílio à pesquisa, processo 2003/13794-3. 


\section{REFERÊNCIAS}

BATAGLIA O; FURLANI AMC; TEIXEIRA JPF; FURLANI PR; GALLO JR. 1983. Métodos de análise química de plantas. Campinas: IAC. 48p.

BOEING G. 2002. Fatores que afetam a qualidade da cebola na agricultura familiar catarinense. Florianópolis: Instituto CEPA/SC. $88 \mathrm{p}$.

BREWSTER JL. 1994. Onions and other vegetable Alliums. Wallingford: UK.CAB International. 236p.

EMBRAPA. 1999. Sistema Brasileiro de Classificação de Solos. Rio de Janeiro: Embrapa Solos. 412p.

FAQUIN V. 1994. Nutrição Mineral de Plantas. Lavras: ESAL/FAEPE. 227p.

FILGUEIRA FAR. 2003. Novo manual de olericultura: agrotecnologia moderna na produção e comercialização de hortaliças. 2ed. Viçosa: UFV. 412p.

FONTES PCR. 1998. Cultura da cebola. Viçosa: UFV. 40p.

GAMIELY S; RANDLE WM; MILLS HA; SMITTLE DA. 1991. Onion plant growth, bulb quality, and water uptake following ammonium and nitrate nutrition. HortScience 26: 1061-1063.

GLASS ADM. 1989. Plant nutrition: an introduction to current concepts. Boston: Jones and Bartlett Publishers. 234p.
GOTO R. 1983. Efeito de doses de diferentes adubos orgânicos na cultura de cebola (Allium cepa L.) de verão. Botucatu-SP: UNESP. 78p. (Dissertação Mestrado).

HAAG HP; HOMA P; KIMOTO T. 1970. Nutrição mineral de hortaliças. VIII. Absorção de nutrientes pela cultura da cebola. Anais... ESCOLA SUPERIOR DE AGRICULTURA “LUIZ DE QUEIROZ”, Piracicaba. p. 143 153.

HAAG HP; OLIVEIRA GD de; BARBOSA V; SILVA NETO JM de. 1981. Marcha de absorção de nutrientes pelo tomateiro (Lycopersicum esculentum Mill) destinado ao processamento industrial. In: HAAG HP MINAMI K. Nutrição mineral de hortaliças. Campinas: Fundação Cargill. p. 447-474.

MALAVOLTA E. 1980. Elementos de nutrição mineral de plantas. Piracicaba: Agronômica Ceres. 251p.

MALAVOLTA E; VITTI GC; OLIVEIRA SA de. 1997. Avaliação do estado nutricional das plantas: princípios e aplicações. 2.ed. Piracicaba: POTAFOS. 319p.

MARSCHNER H. 1995. Mineral nutrition of higher plants. 2.ed. London: Academic Press. $889 \mathrm{p}$.

NASREEN S; HAQ SMI; HOSSAIN MA. 2003. Sulphur effects on growth responses and yield of onion. Asian Journal of Plant Sciences 2: 897-902.

PEREIRA PRG; FONTES PCR. 2005. Nutrição Mineral de Hortaliças. In: FONTES PCR (ed). Olericultura: teoria e prática. Viçosa. p. 39-55.
TEI F; SCAIFE A; AIKMAN DP. 1996. Growth of lettuce, onion, and red beet. 1.Growth analysis, light interception, and radiation use efficiency. Annals of Botany. p. 633-643.

TRANI PE; RAIJ B van. 1997. Hortaliças. In: RAIJ B van; CANTARELLA H; QUAGGIO JA; FURLANI AMC(eds). Recomendações de adubação e calagem para o Estado de São Paulo. 2.ed. Campinas: IAC. p. 157-185. (Boletim técnico, 100).

VIANELLO RL; ALVES AR. 1991. Meteorologia básica e aplicações. Viçosa: UFV. Imprensa Universitária. 449p.

VIDIGAL SM; PEREIRA PRG; PACHECO DD 2002. Nutrição mineral e adubação de cebola. In: Informe Agropecuário 23: 36-50.

VIDIGAL SM; PEREIRA PRG; PACHECO DD; FACION CE. 2003. Acumulação de matéria fresca e seca pela cebola. In: CONGRESSO BRASILEIRO DE OLERICULTURA, 43. Resumos... Recife: SOB (CD-ROM).

VITTI GC; BOARETTO AE; PENTEADO SR. 1994. Fertilizantes e fertirrigação. In: SIMPÓSIO BRASILEIRO SOBRE FERTILIZANTES FLUIDOS. 1. Anais... Piracicaba: Associação Brasileira para Pesquisa da Potassa e do Fosfato. p. 261-280.

WIEDENFELD R. 1994. Nitrogen rate and timming effects on onion growth and nutrient uptake in a subtropical climate. Subtropical Plant Science 46: 32-37.

ZINK FM. 1962. Growth and nutrient absorption of green bunching onions. Proceedings of the American Society for Horticultural Science 80: 430-435 